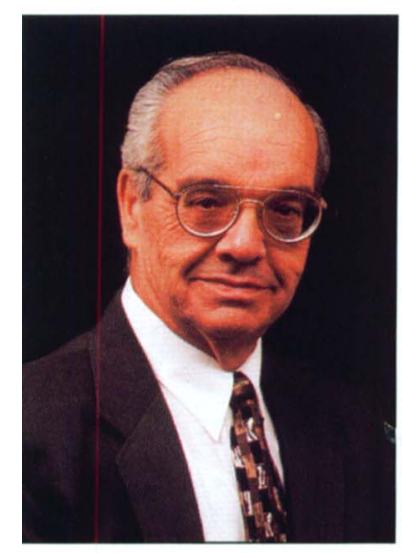

\title{
New facilities to foster solutions for exotic pests
}

\author{
W.R. GOMES \\ Vice President \\ Agriculture and Natural Resources
}

D uring the last century, 4,500 plants and animals of foreign origin have established themselves in the United States in many cases to our benefit. Agriculture is based on such "exotics" as cattle, wheat and soybeans.

The minority of alien species that become "exotic pests," however, loom large in their destructive power. Robert Metcalf, former director of UC's Center for Exotic Pest Research, estimated that exotic pests do aggregate damage to the Golden State of $\$ 3$ billion a year - that's $\$ 100$ per Californian.

The good news is that new technologies such as genetic engineering, combined with classical biological control methods pioneered at UC since the turn of the century, promise to provide a new generation of powerful solutions to exotic pests. However, research in this arena has long been hampered by inadequate research facilities at $\mathrm{UC}$ and throughout the western United States, as well as in other vulnerable states such as Florida and Texas, and at the U.S. Department of Agriculture (USDA).

To perform the needed research, scientists require state-ofthe-art quarantine and physical containment facilities. Such facilities would enable them to safely investigate exotic parasites, microorganisms, and predators, as well as genetically engineered organisms such as disease-resistant plants or more potent microbial insecticides.

UC's current facilities are antiquated, outdated and seismically unsafe. In 1991, recognition of this situation by both the state and federal governments inspired the UC alternative pest research containment and quarantine facilities project. The project called for financing through matching state and federal funds, and three-way participation by UC, CDFA and USDA.

To date, we have received $\$ 10.5$ million to complete phase 1 , the construction of an insectary and quarantine facility at UC Riverside. In addition, the state Legislature has agreed to fund its $50 \%$ share of the $\$ 27$ million UC Davis containment research facility. Congress is now reviewing the final installment of federal support, the remaining $50 \%$ match needed.

UC Riverside's state-of-the-art biological control facility will more than quadruple UCR's capacity to serve the Western Region and the nation in the importation, evaluation and rearing of natural enemies. In addition, a limited number of highsecurity areas will permit research on transgenic insects and plants. Scheduled for completion early in 2000, the facility's groundbreaking will take place July 2 .

The UC Davis facility, focusing on biotechnological as well as traditional quarantine approaches to pest management, will dramatically enhance UC's ability to use new technologies to fight myriad exotic pests. The facility's most unique feature will be 18 greenhouse compartments, all hermetically sealed with break-resistant, dual-paned glass to guarantee that research is contained in the facility. All air into and out of the work areas will be filtered and all solid and liquid waste entering and leaving the facility will be sterilized to protect the research and the environment.

Researchers will use the Davis facilities on a temporary basis to complete the portions of research requiring maximum security. This "hotel" concept will permit use by an array of investigators, both UC scientists and collaborating researchers from state, federal and international agencies.

What specifically can be done in such a contained environment that otherwise cannot be done? To date, the lack of upto-date quarantine facilities has restricted the importation of exotic beneficial insects for research; the lack of secure containment facilities has virtually prohibited the use of exotic pests for research. Such research, if performed in a contained, highly secured facility, can yield vital information. For instance, when a new pest is introduced into one area of the state, such research could reveal the extent of its potential damage, and what control agents might be most useful in its eradication.

Research of this kind would only be conducted after obtaining proper reviews and permits from agencies governing exotic species' importation, such as the USDA Animal and Plant Health Inspection Service and the CDFA. Exotic pests for which research is now severely restricted by quarantine regulations include:

- Tomato yellow leaf curl virus (see p. 23), a geminivirus that causes a severe disease in tomato, and is expected to reach the United States soon.

- Brown citrus aphid (see p. 26), a highly efficient vector of citrus tristeza virus (CTV), which was detected in Florida in 1995 and has spread throughout that state.

- Striga, a serious agricultural weed, which has caused yield losses of millet and sorghum up to $90 \%$ in Africa.

By granting the final installment for the new UC Davis facility, Congress will truly establish a three-way partnership between UC, the state and the federal government. The new facilities will enable scientists to create a national barrier against invasion by exotic pests, and a powerful research machine to deploy when exotic pests become established. This investment is leveraged by the strongest and broadest contingent of pest management researchers in the world. Ultimately, it will pay for itself many times over. 